\title{
Pulsed radiofrequency ablation of median nerve in a patient with soft tissue sarcoma
}

\author{
Nagalaxmi Patnala, ${ }^{1, *}$ \\ ${ }^{1}$ Department of Pain Medicine, Krishna Institute of Medical Sciences, Minister Road, Secunderabad-500003, Telangana, India
}

\begin{abstract}
Pulsed radiofrequency (PRF) is a novel therapeutic modality with many potential applications in pain management. A 14-year-old male patient with soft tissue sarcoma of right hand in the first and second interdigital cleft came with complaints of severe pain in the region of the swelling. On polypharmacy, including narcotics, the patient had a Visual Analog Score (VAS) of 9/10. A diagnostic ultrasound guided median nerve block was given with local anaesthetic and steroid, which decreased the VAS score to 2-3/10. The pain recurred after 4 weeks and pulsed radiofrequency ablation of the median nerve was done. The VAS score now is $2 / 10$ and the patient is comfortably using his hand.
\end{abstract}

Keywords: Soft tissue sarcoma; polypharmacy; ultrasound; median nerve; pulsed radiofrequency; visual analog score

\begin{abstract}
*Corresponding author: Dr. Nagalaxmi Patnala, MD., DNB., FIPM (Fellow in pain management), Department of Pain Medicine, Krishna Institute of Medical Sciences, Minister Road, Secunderabad-500003, Telangana, India. Mobile: 9885652104; Email: nagu.patnala@gmail.com

Received 7 July 2018; Revised 28 August 2018; Accepted 4 September 2018; Published 12 September 2018

Citation: Patnala N. Pulsed radiofrequency ablation of median nerve in a patient with soft tissue sarcoma. J Med Sci Res. 2018; 6(4):125-127. DOI: http://dx.doi.org/10.17727/JMSR.2018/621

Copyright: (C) 2018 Patnala N et al. Published by KIMS Foundation and Research Center. This is an open-access article distributed under the terms of the Creative Commons Attribution License, which permits unrestricted use, distribution, and reproduction in any medium, provided the original author and source are credited.
\end{abstract}

\section{Introduction}

The most common indication for a median nerve block is carpal tunnel syndrome where the nerve gets compressed by the thickened flexor retinaculum for which surgical release is the treatment of choice. For cases with recurrent carpal tunnel syndrome and other causes of pain in the region of median nerve an ultrasound guided median nerve block can be given followed by pulsed radiofrequency (PRF) for prolonged relief [1].

Cancer pain, like pain due to soft tissue sarcoma, in this patient requires multimodal analgesia. Pain is treated according to the WHO ladder including narcotics like morphine in severe pain. Interventional pain procedures play a pivotal role in cases with severe intractable pain, where patients do not respond or are intolerant to polypharmacy. 


\section{Current accepted allopathic or traditional approaches to treatment}

Around two-thirds of cancer patients experience severe pain. Approximately $30-50 \%$ of patients experience pain while undergoing treatment and 70$90 \%$ of patients with advanced cancer experience pain on treatment.

Cancer pain is treated according to the WHO ladder $[2,3]$. The pain initially is treated with NSAIDS, acetaminophen and mild opioids. With increasing severity strong opioids like the morphine are recommended. Interventional pain procedures play a pivotal role in cases with severe intractable pain, where patients do not respond or are intolerant to polypharmacy.

\section{Case report}

A 14-year-old male patient presented with injury to the right hand while playing. The swelling progressively increased in size in the first and second interdigital cleft with pus discharging (Figure 1). The patient was treated with analgesics and antibiotics. The pus decreased but the swelling progressively increased. The patient had severe pain in the region of swelling with a VAS score of 9/10.

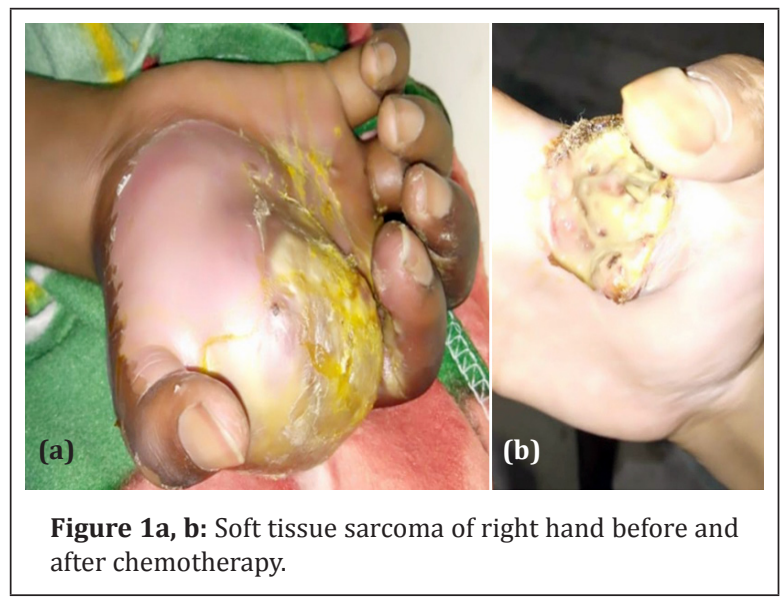

The patienthadaswelling in thefirstinterdigital space of right hand with pus discharging. MRI right hand showed soft tissue sarcoma which was confirmed by biopsy [4]. Treatment with chemotherapy and antibiotics were initiated. NSAIDS and mild opioids were started to control pain. Pain decreased only marginally, hence patient was started on the strong opioid morphine to decrease pain, which he could not tolerate.
To decrease pain ultrasound guided right median nerve block with local anaesthetic and steroid was given (Figure 2) [5]. The VAS score decreased from $9 / 10$ to $3 / 10$. The pain recurred after 4 weeks for which PRF Ablation of right median nerve was done to obtain prolonged relief. The VAS score after the procedure was $2 / 10$.

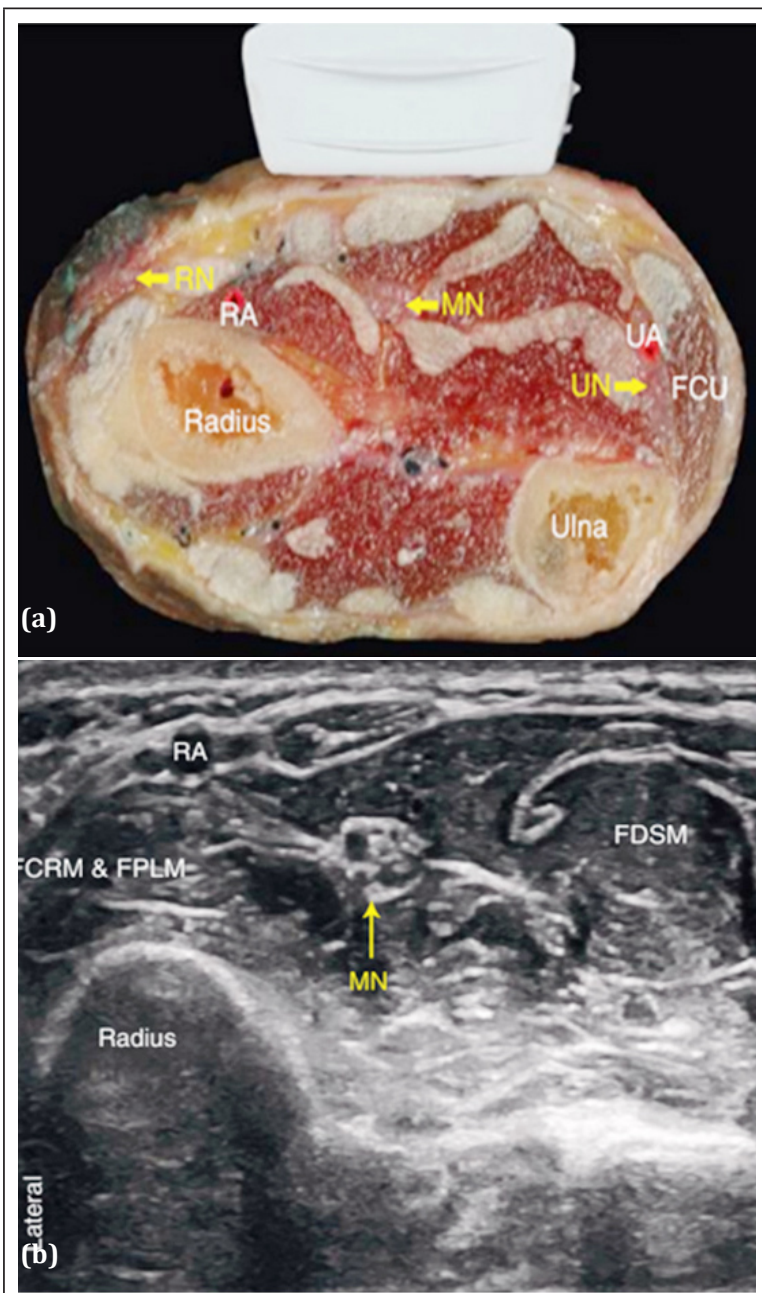

Figure 2a, b: Sonoanatomy of hand (MN: Median nerve, FCRM: Flexor carpi radialis muscle, FPLM: Flexor pollicis longus muscle, FDSM: Flexor digitorum superficialis muscle, RA: Radial artery).

\section{Results of treatment and follow up studies}

Ultrasound guided median nerve block decreased the VAS score from $9 / 10$ to $2-3 / 10$. The steroid block was short-lived, so it was followed by PRF ablation for long term relief.

The patient was first treated with mild analgesics like NSAIDS, tramadol, acetaminophen and tapentadol. With increasing pain, strong opioids like morphine 
were added for pain relief. Ultrasound guided right median nerve block [6] was given with local anaesthetic and steroid ( $3 \mathrm{ml}$ of $0.25 \%$ bupivacaine with $40 \mathrm{mg}$ triamcinolone) (Figure 3). The median nerve crosses the elbow medial to the brachial artery and courses towards the wrist deep to the flexor digitorum superficialis in the centre of the forearm. As the muscles taper towards the tendons near the wrist, the nerve assumes an increasingly superficial position until it is located beneath the flexor retinaculum in the carpal tunnel. A linear transducer placed transversely at the level of the wrist crease will reveal a cluster of oval hypoechoic structure which can be confused with the tendons. Sliding the transducer $5-10 \mathrm{~cm}$ proximally to the volar side of the forearm, the tendons disappear and the nerve location can be confirmed and blocked.

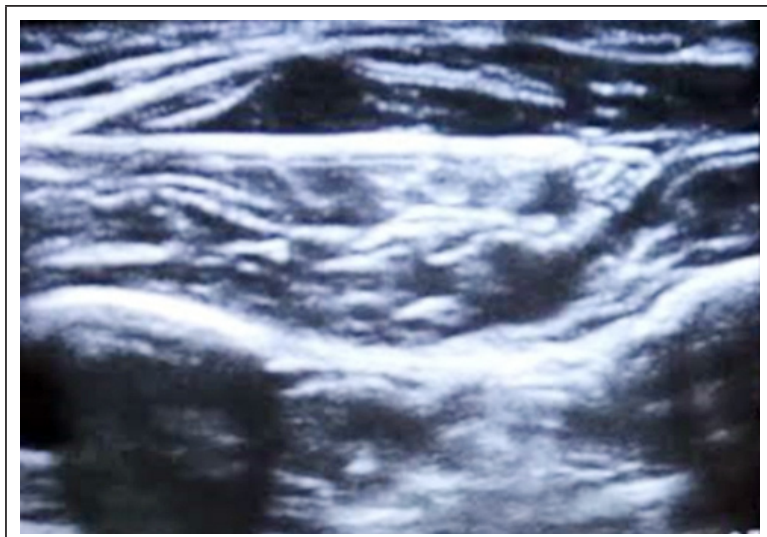

Figure 3: Needle on median nerve.

PRF is a novel therapeutic modality with many potential applications in pain management. It uses radiofrequency current in short (20 ms), high voltage bursts; the "silent" phase (480 ms) of PRF allows time for heat elimination, generally keeping the target tissue below $42^{\circ} \mathrm{C}$. Two cycles of 180 seconds each was done to block the median nerve [7].

\section{Discussion}

PRF ablation offers the advantage of pain control without tissue destruction and painful sequelae associated with conventional radiofrequency ablation (CRF) [8]. This theoretical benefit of PRF is especially alluring in cases of neuropathic pain in which CRF is relatively contraindicated.

Pulsed RF can be used without concern of producing sensory or motor loss. Since there is no satisfactory surgical solution for patients with this kind of chronic pain, this mode of treatment offers a potentially valuable alternative against maintaining patients on chronic opiate therapy. In addition, it may offer an advantage over steroids when one considers the reports of adverse outcomes associated with repeated steroid use [9].

\section{Conclusion}

Due to the absence of tissue destruction by pulsed RF, it can be used for various conditions to treat chronic pain like radiculopathy or peripheral neuralgia.

\section{Acknowledgement}

I am thankful to the patient and his parents for publication. I am thankful to Dr. B. Bhaskar Rao, MD \& CEO, KIMS Hospitals, Dr. R.V. Rao, Senior Medical Oncologist, KIMS Hospitals, Dr. C. Naresh Kumar Reddy, HOD, Department of Anaesthesiology, KIMS Hospitals, Secunderabad.

\section{Conflicts of interest}

Author declares no conflicts of interest.

\section{References}

[1] Chen LC, Ho CW, Sun CH, Lee JT, Li TY, et al. Ultrasound guided pulsed radiofrequency for carpal tunnel syndrome: A single blinded randomized controlled study. PLoS One. 2015; 10(6):e0129918.

[2] Kamal Kumar Fotedar. WHO ladder- Relevance in today's world. Int J Periop Ultrasound Appl Technol. 2013; 2(2):4953.

[3] Carlson CL. Effectiveness of the World Health Organization cancer pain relief guidelines: An integrative review. J Pain Res. 2016; 9:515-534.

[4] Singer S, Demetri GD, Baldini EH, Fletcher CD. Management of Soft tissue sarcomas- An overview and update. Lancet Oncol. 2000; 1(2):75-85.

[5] Brown MR, Farquhar-Smith P, Williams JE, ter Haar G, deSouza NM. The use of high intensity focused ultrasound as a novel treatment for painful conditions- a description and narrative review of the literature. Br J Anaesth. 2015; 115(4):520-530.

[6] A Capek, Dolan J. Ultrasound guided peripheral nerve blocks of the upper limb. Br J Anaesth. 2015; 15(3):160-165.

[7] Haider N, Mekasha D, Chiravuri S, Wasserman R. Pulsed radiofrequency of the median nerve under ultrasound guidance. Pain Physician. 2007; 10(6):765-770.

[8] Sluijter ME, Imani F. Evolution and mode of action of pulsed radiofrequency. Anesth Pain Med. 2013; 2(4):139-141.

[9] Lindquist J, Backryd E. Pulsed radiofrequency in clinical practice- A retrospective analysis of 238 patients with chronic non cancer pain treated at an academic tertiary pain centre. Scand J Pain. 2016; 12:68-73. 